\begin{tabular}{|c|c|c||c|c|c|c|c|}
\hline JOURNAL OF EDUCATION, SCIENCE AND HEALTH - JESH \\
Revista de Educação, Ciência e Saúde \\
DOI: https://www.doi.org/10.52832/jesh.v2i1.76 \\
Home page: www.jeshjournal.com.br \\
e-ISSN: $2763-6119$
\end{tabular}

\title{
PANDEMIA E TECNOLOGIA: A TECNOFOBIA COMO TEMA EMERGENTE POR MEIO DE UMA SEQUÊNCIA DIDÁTICA
}

\author{
PANDEMIC AND TECHNOLOGY: TECHNOPHOBIA AS EMERGING TOPIC THROUGH A DIDACTIC \\ SEQUENCE
}

\section{PANDEMIA Y TECNOLOGÍA: LA TECNOFOBIA COMO TEMA EMERGENTE A TRAVÉS DE UNA SECUENCIA DIDÁCTICA}

\section{Mauricio de Oliveira Silva ${ }^{*}$; Marcos Anjos de Moura ${ }^{\text {iD }}$; Tainan Amorim Santana ${ }^{3 *}$}

\begin{abstract}
${ }^{1}$ Doutorando em Agroecologia e Desenvolvimento Territorial (UNIVASF). Mestre em Ciências Ambientais (UESB). Especialista em Educação e Direitos Humanos (Alfa América). Especialista em Serviço Social e Saúde Coletiva (Faculdade Estratego). Licenciado em Ciências Biológicas (UESB). Professor da rede municipal de Vitória da Conquista -BA(SMED), Vitória da Conquista, Bahia, Brasil; ${ }^{2}$ Doutorando em Ecologia e Conservação da Biodiversidade (UESC). Mestre em Ciências Ambientais (UESB). Especialista em Ensino de Ciências Naturais e Matemática (IFBAIANO). Licenciado em Ciências Biológicas (UESB), Itapetinga, Bahia, Brasil; ${ }^{3}$ Doutora em Educação (UFS). Docente (UFRA), Capanema/Pará, Brasil.

*Autores correspondentes: m.osilva@hotmail.com; tainan.santana@ufra.edu.br
\end{abstract}

Recebido: 04/01/2022 | Aprovado: 06/02/2022 | Publicado: 12/02/2022

\begin{abstract}
Resumo: A educação é peça fundamental no desenvolvimento de uma sociedade mais justa e plural. Nos tempos de pandemia houve a necessidade de readaptação das aulas presenciais para o ensino remoto, porém, alguns novos problemas podem surgir a partir disso, como a tecnofobia. O objetivo dessa pesquisa foi apresentar a temática tecnofobia aos educandos do Ensino Fundamental II e a partir disso, aplicar um questionário para perceber se algum aluno sentiu sintoma/as de tecnofobia durante as aulas remotas e justifica-se pela necessidade de compreensão de como a mudança na forma de ensino pode afetar a saúde mental dos estudantes. O estudo foi conduzido e duas turmas, referentes a uma turma de Educação de Jovens e Adultos (EJA) $8^{\circ}$ e $9^{\circ}$ e uma do $9^{\circ}$ ano regular a partir da metodologia quali-quantitativa e de pesquisa-ação por meio de uma sequência didática. Pela pesquisa foi possível levar aos alunos conhecimentos básicos sobre a tecnologia no nosso cotidiano e apresentar o transtorno da tecnofobia, além de capacitar na identificação e busca de soluções sobre esse novo transtorno psicossocial, esclarecer os problemas da situação de estudo, ampliar o conhecimento científico acerca da tecnologia e da tecnofobia e com isso ampliar o nível de consciência quanto a problemática da tecnofobia no nosso cotidiano, outrossim, as aulas remotas podem ter afetado a vida estudantil dos entrevistados, já que apontaram sintomas como sentir-se distante da realidade, tontura e ficarem irritados e abrem discussões do quanto a tecnologia pode substituir o ensino presencial e as inter-relações do universo escolar.
\end{abstract}

Palavras-chave: Aula remota. Ensino e aprendizagem. Sequência didática.

Abstract: Education is a fundamental part of the development of a more just and plural society. In times of a pandemic, there was a need to readaptation of face-to-face classes for remote teaching, however, some new problems may arise from this, such as technophobia. The objective of this research was to present the technophobia theme to Elementary School II students and from that, apply a questionnaire to see if any student felt symptoms of technophobia during remote classes and is justified by the need to understand how the change in the way of teaching can affect the mental health of students. The study was conducted in two groups, referring to a group of Youth and Adult Education (EJA) 8th and 9th and one of the 9th regular year, based on the qualitative-quantitative and action research methodology through a didactic sequence. Through the research, it was possible to provide students with basic knowledge about technology in our daily lives and to present the technophobia disorder, in addition to training in the identification and search for solutions about this new psychosocial disorder, clarifying the problems of the study situation, expanding scientific knowledge about of technology and technophobia and thereby increase the level of awareness regarding the problem of technophobia in our daily lives, in addition, remote classes may have affected the student life of the interviewees, as they pointed out symptoms such as feeling distant from reality, dizziness and become irritated and open discussions on how much technology can replace face-to-face teaching and the interrelationships of the school universe.

Keywords: Remote class. Teaching and learning. Didactic sequence. 
Resumen: La educación es parte fundamental del desarrollo de una sociedad más justa y plural. En tiempos de pandemia, surgió la necesidad de readecuación de las clases presenciales para la enseñanza a distancia, sin embargo, de ello pueden surgir algunos problemas nuevos, como la tecnofobia. El objetivo de esta investigación fue presentar el tema de la tecnofobia a los estudiantes de la Enseñanza Básica II y a partir de ello, aplicar un cuestionario para ver si algún estudiante sintió síntomas de tecnofobia durante las clases a distancia y se justifica por la necesidad de comprender cómo se produce el cambio en la forma de la enseñanza puede afectar la salud mental de los estudiantes. El estudio se realizó en dos grupos, referente a un grupo de Educación de Jóvenes y Adultos (EJA) de $8^{\circ}$ y $9^{\circ}$ y uno de $9^{\circ}$ año regular, basado en la metodología de investigación cualitativa-cuantitativa y acción a través de una secuencia didáctica. A través de la investigación se logró brindar a los estudiantes conocimientos básicos sobre la tecnología en nuestro cotidiano y presentar el trastorno tecnofobia, además de capacitarlos en la identificación y búsqueda de soluciones sobre este nuevo trastorno psicosocial, esclareciendo la problemática de la situación de estudio., ampliando el conocimiento científico sobre la tecnología y la tecnofobia y con ello aumentar el nivel de conciencia respecto al problema de la tecnofobia en nuestra vida cotidiana, además, las clases a distancia pueden haber afectado la vida estudiantil de los entrevistados, pues señalaron síntomas como sentirse distantes de la realidad, se marean y se irritan y abren discusiones sobre cuánto la tecnología puede reemplazar la enseñanza presencial y las interrelaciones del universo escolar.

Palabras-clave: Clase a distancia. Enseñando y aprendiendo. Siguiendo la enseñanza.

\section{INTRODUÇÃO}

A educação é uma das formas de mudanças na estrutura da sociedade, é por meio dela que as transformações sociais são alcançadas. Como já dizia Paulo Freire (1979, p.84) "a educação não transforma o mundo. Educação transforma pessoas, pessoas transformam o mundo". É necessário perceber que as mudanças na sociedade afetam a forma como a educação chega e atende as pessoas, principalmente as crianças e adolescentes, e nesse quesito, desde o ano de 2020, trouxe um novo desafio: como manter as crianças estudando em meio a uma pandemia?

Para entender como isso tudo ocorreu, primeiro deve-se entender o que é essa pandemia. Para tal, um breve histórico deve ser apresentado. Em 2019, um surto de coronavírus em Wuhan, China, começou a se espalhar por todo o país (Xing \& Zhi, 2020). As possíveis causas foram excluídas uma a uma, incluindo influenza, influenza aviária, adenovírus, coronavírus da síndrome respiratória aguda grave (SARS-CoV) e coronavírus da síndrome respiratória do Oriente Médio (MERS-CoV) (Xing \& Zhi, 2020).

Depois de vários estudos e exclusão das causas, em 3 de janeiro de 2020, a China informa a pandemia a Organização Mundial de Saúde (OMS) e em 7 de janeiro o novo patógeno é descrito, o 2019-NcoV, ao qual a OMS nomeia de Covid-19 (Xing \& Zhi, 2020). Em 11 de março de 2020, a Organização Mundial de Saúde (OMS) declarou a Covid-19 uma pandemia, doença causada pelo novo coronavírus (SARS-CoV-2) (Sociedade Brasileira de Infectologia, 2020). Na data de 12 de março de 2020, foram confirmadas 125.048 pessoas contaminadas em todo o mundo com uma taxa de mortalidade 3,7\%, comparado a gripe que apresenta uma taxa de 1\% (Mehta et al., 2020), com taxas de contaminação crescentes no mundo todo.

Nesse novo cenário, em março de 2020, sem existência de medicamentos ou vacinas contra a Covid-19, as medidas mais eficazes e eficientes de controle eram voltadas a prevenção. Rapidamente, medidas como a higienização das mãos com água e sabão, álcool em gel, isolamento de pessoas acometidas pela doença, distanciamento social e utilização de máscaras pelas pessoas que precisassem sair de casa para realização de serviços essenciais foram noticiadas e, com isso, diversos setores foram fechados por meio de decretos federais, 
estaduais e municipais pelo mundo, incluindo o Brasil e abrangendo as escolas, sem previsão de retorno presencial.

A forma de ensino presencial foi totalmente inviabilizada, e medidas de levar educação para as crianças e adolescentes começaram a ser pensadas, em meio ao medo, ao desespero e incertezas, a forma mais consensual de ensino foi via forma remota, quer seja com impressões e buscas na escola, atendimentos via aplicativos de mensagens, via redes sociais, síncronas por programas de videochamadas ou por plataformas que disponibilizassem o material on-line.

Essa chegada ou imposição metodológica forçada da tecnologia na área educacional levanta debates dentro do eixo tecnologia, seus usos, problemas, utilizações positivas e negativas. Ao compreender que "a tecnologia é assumida como um bem social e, justamente com a ciência, é o meio para agregação de valores aos mais diversos produtos, tornando-se chave para a competitividade estratégica e desenvolvimento econômico de uma sociedade” (Maranhão, 2015, p. 1), deve-se apontar também as questões que podem ser prejudiciais, dentre eles, foi identificado o tema tecnofobia. A tecnofobia é uma aversão as tecnologias ou um medo exagerado que impede o uso de aparelhos tecnológicos por uma pessoa.

O tecnofóbico é alguém que, por não ser um nativo digital (geração que nasceu imersa nessa cultura), acaba criando aversão a tecnologias digitais. Entre professores da geração X e Baby Boomers, esse comportamento, em certa medida, ainda persiste. Isso ocorre porque boa parte deles sente dificuldades de aprender a usar esses novos equipamentos, acabando por acomodar-se e desistir do uso das tecnologias digitais (Schoch, 2016, p. 2).

Com as mudanças na forma de ensino, os estudantes e professores passaram a utilizar as telas de notebooks, tablets e smartphones para lecionar e participar das aulas, porém, alguns problemas foram observados de forma empírica, desde a falta de material, acesso à internet e, mesmo, a geração de problemas psicossomáticos como a tecnofobia, tema proposto para essa pesquisa.

Assim, as sequências didáticas (SD) por serem elaboradas etapa por etapa é uma importante ferramenta que contribui de forma efetiva no processo de ensino e aprendizado e ainda, contornar quanto a resistência dos alunos ao uso das tecnologias. Apresentam um conjunto de atividades ordenadas e que a aplicação dessas tecnologias vai surgindo de forma natural e sequenciada de acordo as etapas da SD, tendo objetivos educacionais (Moura, Silva \& Leal, 2021).

Conforme a necessidade, as tecnologias digitais vão sendo apresentadas com a aplicação da SD em etapas: a primeira (Explanação do conceito): explana sobre os diferentes conceitos bases que servem para o entendimento do tema abordado; a segunda etapa (Problematização do conceito), aplicação e exemplificação com situações problemas aplicados com fenômenos científicos que retratam o cotidiano e é feito um aprofundamento entre teoria e prática, a terceira etapa (Aplicação do conceito), visa cumprir com as exigências obrigatórias do currículo, repensando nas diferentes avaliações, assim é possível tentar superar o ensino tradicional, tão criticado (Silva, 2019; Silva \& Moura, 2021).

Nesse sentido, o objetivo dessa pesquisa foi apresentar a temática tecnofobia aos educandos do Ensino Fundamental II e a partir disso, aplicar um questionário para perceber se algum aluno sentiu sintoma/as de 
tecnofobia durante as aulas remotas e justifica-se pela necessidade de compreensão de como a mudança na forma de ensino pode afetar a saúde mental dos estudantes.

\section{MATERIAL E MÉTODOS}

A partir do tema tecnologia, estudado em ciências, foi pensado na forma com que os aparelhos tecnológicos e as novas tecnologias vêm afetando o nosso cotidiano. Pensando nisso, o tema tecnofobia foi escolhido para buscar entender como que esse uso e acesso constantes a essas novas ferramentas podem influenciar na saúde mental dos alunos.

\section{1 Área de Estudo e Público-alvo}

O estudo foi conduzido em uma turma de Educação de Jovens e Adultos (EJA) referentes aos $8^{\circ}$ e $9^{\circ}$ ano e em uma turma do $9^{\circ}$ ano regular do Ensino Fundamental II, de uma Escola Municipal, localizada no Bairro Jardim Valéria em Vitória da Conquista, Bahia, nordeste do Brasil (Figura 1), com um total de 66 alunos matriculados.

Figura 1- Mapa de Vitória da Conquista, Bahia, nordeste do Brasil.

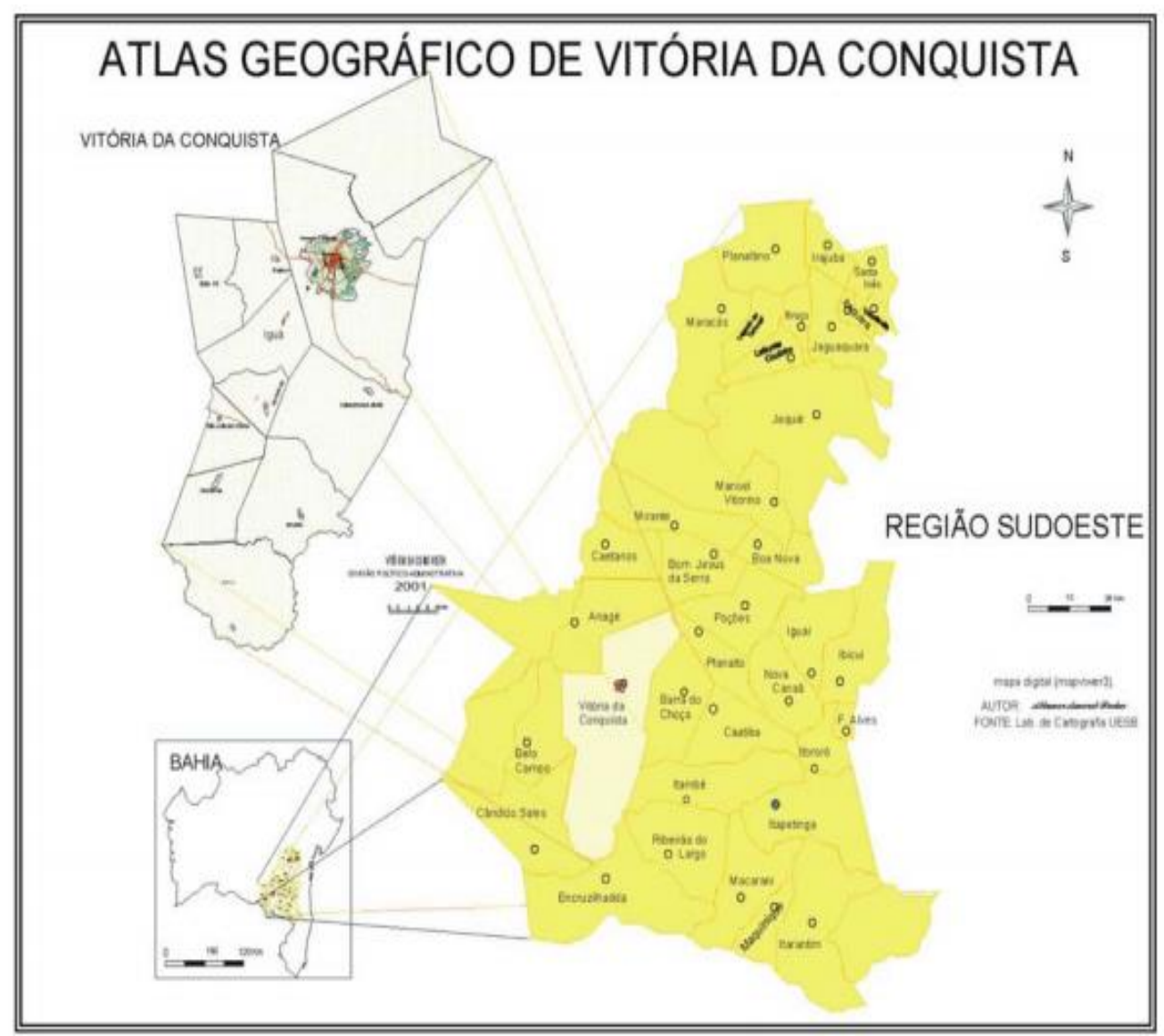

Fonte: Rocha e Ferraz, 2005.

Vitória da Conquista é uma cidade metrópole, ou também chamada capital regional, de oitenta municípios da região sudoeste da Bahia e de dezesseis do norte de Minas Gerais (Porto; Santana-Júnior \& 
Nascimento, 2017; Conselho Regional de Corretores de Imóveis da Bahia -CRECI-BA, 2018). É a terceira maior cidade da Bahia, abriga uma população de aproximadamente 343 mil pessoas e tem um nível de escolarização de pessoas entre os 6 a 14 anos de idade de 96,8\% (Instituto Brasileiro de Geografia e Estatística, 2021).

\subsection{Metodologia da pesquisa}

A pesquisa foi conduzida e avaliada sobre os princípios quali-quantitativa e de pesquisa-ação. De acordo Flick (2009) a condução e o tratamento dos dados em uma pesquisa científica podem ocorrer de forma tanto qualitativa, quanto quantitativa, ou simplesmente se complementarem quali-quantitativa ocorrendo uma melhor análise, discussão e resultados finais com duas perspectivas e múltiplas análises. Flick (2009) acrescenta que a combinação dos dois métodos fornece uma análise uma visão geral do estudo. Nessa vertente, para Schneider, Fujii \& Corazza (2017), o método quali-quantitativa possibilita uma análise processual com o método qualitativo e com o método quantitativo uma abordagem estrutural do fenômeno.

Segundo Moura, Silva \& Leal (2021), todo o processo de elaboração, aplicação, avaliação de uma SD, na Etapa 1, inferência de conceitos, na Etapa 2, investigação da situação problema e na Etapa 3, visando soluções e avaliação caracterizam assim, como uma pesquisa-ação sendo uma estratégia metodológica tem como objetivos para o seu desenvolvimento, dentre outros:

\footnotetext{
a) Conceder aos pesquisadores e os agentes alvo da pesquisa as condições de se tornarem capazes de buscar as soluções para seus problemas reais, realizando ações de transformação e de reflexão; b) Possibilitar a resolução de problemas de diferentes naturezas ou, pelo menos, em esclarecer os problemas da situação em estudo; c) Ampliar o conhecimento científico acerca de questões relacionadas à lócus da pesquisa; d) Proporcionar as pessoas e grupos participantes da pesquisa a ampliação do nível de consciência quanto a situação problemática detectada. (Thiollent, 1986, p. 8,16).
}

Dessa forma, a pesquisa adotou interpretações entrelaçadas da análise da pesquisa qualitativa e da pesquisa quantitativa. A pesquisa-ação buscou relacionar o aprendizado com a vivência dos educandos inseridos nesse sistema de ensino totalmente novo e dentro de uma realidade cheia de desafios que foi inserida pela pandemia do coronavírus.

\subsection{Caminho metodológico}

Para a execução da pesquisa foi estruturada uma sequência didática (SD) (Quadro 1) composta por três encontros via Google Meet, construída com três encontros de 50 minutos, aulas expositivas-participativas e apresentação de uma cartilha sobre a tecnofobia em tempos de educação remota. 
Quadro 1 - Sequência didática aplicada em sala de aula remota via Google Meet.

\begin{tabular}{|c|c|c|}
\hline Programação & Atividade executada & $\begin{array}{l}\text { Tempo de } \\
\text { aula }\end{array}$ \\
\hline $\begin{array}{l}\text { Aula expositiva-participativa sobre tecnologia } \\
\text { no nosso cotidiano com base na ciência. }\end{array}$ & $\begin{array}{l}\text { Nesse encontro foram apresentados os } \\
\text { benefícios e malefícios provocados pelo avanço } \\
\text { da tecnologia na sociedade; suas aplicações na } \\
\text { saúde, na educação, na agricultura etc. bem } \\
\text { como a poluição e os impactos ambientais } \\
\text { negativos ao meio ambiente. dentro desses } \\
\text { temas foi apresentado brevemente a tecnofobia } \\
\text { como um dos malefícios. }\end{array}$ & 50 minutos \\
\hline $\begin{array}{l}\text { Apresentação da cartilha "Tecnofobia em } \\
\text { tempos de educação remota" em aula } \\
\text { expositiva-participativa. }\end{array}$ & $\begin{array}{l}\text { Nesse segundo encontro foi apresentada a } \\
\text { cartilha que traz a definição do termo } \\
\text { tecnofobia, os sintomas, dados de uma pesquisa } \\
\text { aplicada e a forma de tratamento do transtorno. }\end{array}$ & 50 minutos \\
\hline Aplicação de questionário & $\begin{array}{l}\text { Questionário semiestruturado com oito questões } \\
\text { para levantar dados sobre acesso à internet, } \\
\text { realização das atividades, identificar possíveis } \\
\text { sintomas de tecnofobia e avaliar o aprendizado. }\end{array}$ & via Google Forms \\
\hline
\end{tabular}

Fonte: Elaborado pelos autores, 2020.

\section{$1^{\circ}$ Momento:}

O primeiro encontro foi pensado para introduzir a tecnologia no contexto das ciências, nesse momento foi explicado o conceito de tecnologia, as suas utilizações pela nossa sociedade, as aplicações nas áreas de saúde, meio ambiente, agricultura, educação, comunicação, cultura etc., bem como foram debatidas as questões benéficas como a possibilidade do ensino remoto, os avanços nos exames médicos, no aumento da produção de alimentos, medicamentos, vacinas e outras conquistas positivas e como, malefícios, comentados os impactos negativos no meio ambiente, como poluição, desmatamento e algumas doenças desenvolvidas com o avanço da tecnologia, e nestas, inclui-se o transtorno moderno denominado tecnofobia.

\section{$2^{\circ}$ Momento:}

Antes da apresentação do segundo encontro foi produzida uma cartilha (Figura 2) sobre a tecnofobia em tempos de educação remota (Ramos et al., 2020). A cartilha utilizada foi feita em conjunto com alunos do curso de Psicologia do Centro Universitário UniFTC e ilustrados com personagens da Lourinba e sua turma (Silva, 2021) que foram conduzindo a explicação do tema, para ficar mais atrativa e lúdica aos educandos. Essa cartilha foi utilizada em aula para apresentar o tema aos estudantes. 
Figura 2 - Cartilha sobre tecnofobia utilizada em aula via Google Meet.

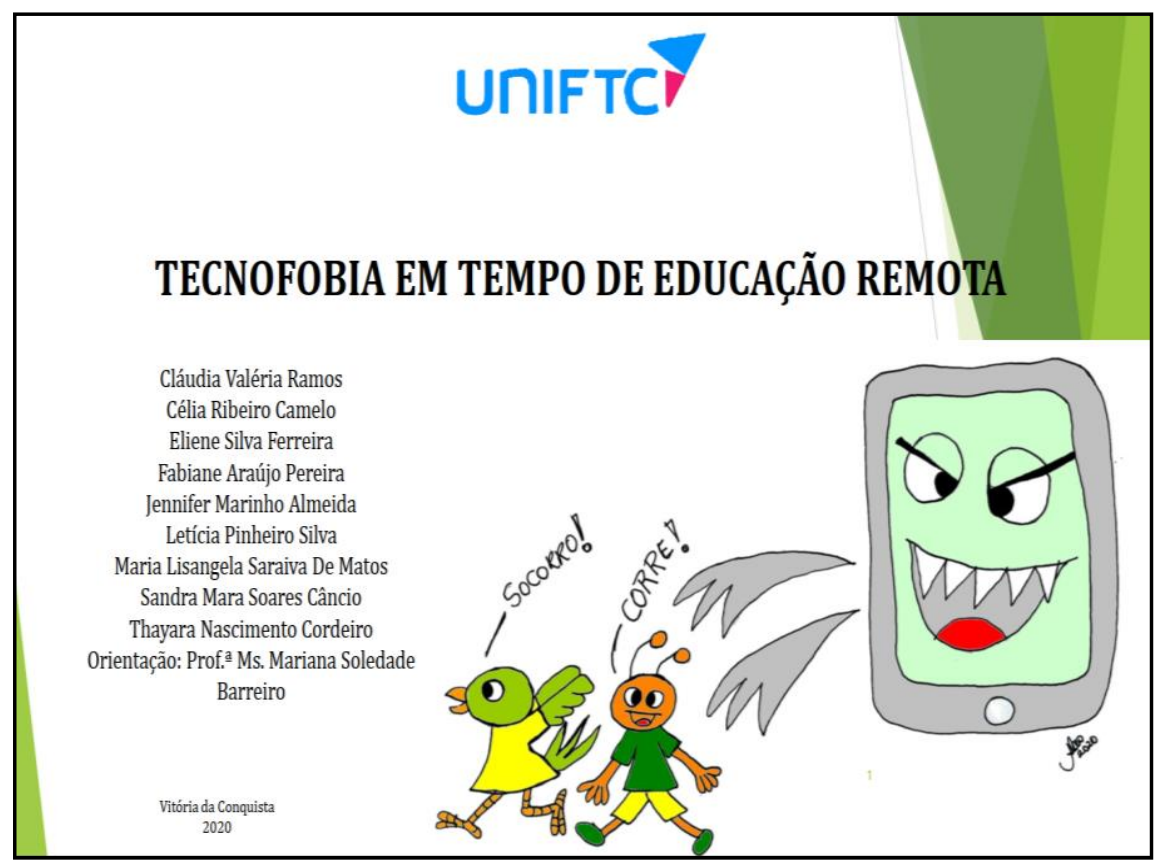

Fonte: Ramos et al., 2020.

\section{$3^{\circ}$ momento:}

Esse terceiro momento foi utilizado para que os estudantes respondessem ao questionário (Quadro 2) via Google Forms para compreender sobre como os alunos estão estudando, como se dá o acesso as aulas, o que eles aprenderam sobre a tecnofobia a partir da aula expositiva-participativa e se apresentaram algum sintoma do transtorno durante o período de aulas remotas.

Quadro 2- Questionário aplicado aos alunos para investigar se algum(a) teve sintoma de tecnofobia durante as aulas remotas.

\begin{tabular}{|c|c|}
\hline Idade & \\
\hline Sexo & $\begin{array}{ll}\text { - } & \text { Feminino } \\
\text { - } & \text { Masculino } \\
\text { - } & \text { Intersexo } \\
\end{array}$ \\
\hline Tem acesso à internet em casa? & $\begin{array}{ll}\text { - } & \text { Sim } \\
\text { - Não } & \text { Nat } \\
\end{array}$ \\
\hline O aparelho que utiliza para fazer as tarefas é de quem? & $\begin{array}{l}\text { - Próprio } \\
\text { - Dos meus pais } \\
\text { - } \quad \text { De um outro parente } \\
\end{array}$ \\
\hline Você já conhecia a tecnofobia? & $\begin{array}{ll} & \text { Sim } \\
\text { - } & \text { Não } \\
\end{array}$ \\
\hline $\begin{array}{l}\text { Você apresentou algum desses sintomas por precisar usar algum } \\
\text { aparelho eletrônico? }\end{array}$ & $\begin{array}{l}\text { - Sensação de perda do fôlego, } \\
\text { - Tontura, } \\
\text { - Palpitações no coração, } \\
\text { - Ficar irritado, } \\
\text { - Perder o controle, } \\
\text { - Sentir-se distante da realidade, } \\
\text { - Ser incapaz de pensar ou falar claramente } \\
\text { - Medo ou receio de usar aparelhos } \\
\text { eletrônicos. }\end{array}$ \\
\hline
\end{tabular}




\begin{tabular}{|l|l|}
\hline $\begin{array}{l}\text { Você acha que conseguiu aprender bem os assuntos pelas aulas } \\
\text { remotas? }\end{array}$ & $\begin{array}{l}\bullet \text { Sim } \\
\text { - Não }\end{array}$ \\
\hline $\begin{array}{l}\text { Caso ache importante deixe aqui algo que considere importante } \\
\text { sobre as aulas remotas (dificuldades, vantagens, etc.) }\end{array}$ & \\
\hline
\end{tabular}

Fonte: elaborado pelos autores, 2021.

\title{
3 RESULTADOS E DISCUSSÃO
}

Foram obtidas 18 respostas, compreendidas por 56\% de alunos do sexo feminino e 44\% do sexo masculino, $78 \%$ da Educação de Jovens e Adultos (EJA) $8^{\circ}$ e $9^{\circ}$ ano e $22 \%$ do $9^{\circ}$ ano regular. Destes, $94 \%$ disseram ter acesso à internet em casa, $72 \%$ tinham o próprio aparelho para realizar as aulas, $22 \%$ utilizam o aparelho do pai ou mãe e 6\% de outro parente. Em pesquisa realizada pelo Centro Regional de Estudos para o Desenvolvimento da Sociedade da Informação - CETIC (2013), foi demonstrado que

\begin{abstract}
A residência do aluno é apontada como o local mais frequente de acesso à Internet, citada por 65\% deles. Entretanto, as lanhouses desempenham um papel importante na inclusão digital de crianças e adolescentes: no Nordeste, por exemplo, $48 \%$ acessam a rede a partir de lanhouses, sete pontos percentuais acima da proporção sobre o total de alunos. Nessa região, a escola também é percebida como um local relevante para o acesso, onde quase metade dos alunos acessa à Internet $-46 \%$. Na região Sul, a escola tem importância muito significativa: $71 \%$ dos jovens acessam a Internet por lá. Por outro lado, o Nordeste está abaixo da média do Brasil: apenas 36\% dos alunos acessam a rede no ambiente escolar (2013, p. 4).
\end{abstract}

Um dado interessante é que em 2020, a proporção de domicílios com acesso à internet chegou a 83\%, o que representa aproximadamente 61,8 milhões de domicílios com algum tipo de conexão à rede (CETIC, 2020). Vale lembrar que "como espaço de inclusão digital, as escolas constituem uma oportunidade concreta para o desenvolvimento de competências e de letramento digital, fundamentais para o trânsito no mundo cultural, educacional e de lazer" (CETIC, 2013, p. 2).

Por outro lado, a mudança do espaço físico para o ambiente de aprendizagem virtual (AVA) ${ }^{1}$ proposto pela Prefeitura Municipal de Vitória da Conquista (PMVC), mesmo que o ideal e mais eficiente para o momento pandêmico, pode ter um dos malefícios que é a tecnofobia, além da exclusão da população mais carente que não tem acesso à internet. Sobre a tecnofobia, $72 \%$ afirmaram que não conheciam o transtorno, enquanto $28 \%$ afirmaram que já conhecia.

Questionados sobre sentir algum sintoma de tecnofobia (Figura 3) durante o período de aulas remotas, os sintomas mais aparentes foram sentir-se distante da realidade (22\%), tontura (21\%) e ficar irritado $(19 \%)$, esses sintomas podem indicar tecnofobia, mas também, está relacionado a mudança brusca de ambiente de aprendizado para o virtual, a falta de conhecimento ao utilizar aparelhos para estudos (não formação em informática e acessibilidade), ao grande tempo dentro de casa que pode gerar tédio e dificultar a convivência familiar, dentre outros.

${ }^{1}$ A Prefeitura Municipal de Vitória da Conquista (PMVC) propôs uma plataforma para o aluno acessar com número de matrícula e baixar as atividades a serem realizadas com tutoria pelos professores via rede social de mensagens e aulas remotas via Google Meet, Whats App, Facebook, dentre outros. Link para site: http://smed.pmvc.ba.gov.br/estudoremoto/login-control/ 
Cunha et al. (2021, p. 9030), apontam que

o Sistema Nervoso Central é diretamente afetado em um contexto de pandemia e mudanças comportamentais e cognitivas podem resultar em desfechos negativos na vida dos indivíduos. Além disso, outros impactos na saúde são relatados, como aumento do consumo de álcool, ganho de peso, diminuição de atividade física, aumento dos níveis de cortisol e acentuação de outros transtornos psiquiátricos.

Figura 3 - sintomas ligados a tecnofobia apontados pelos alunos durante as aulas remotas.

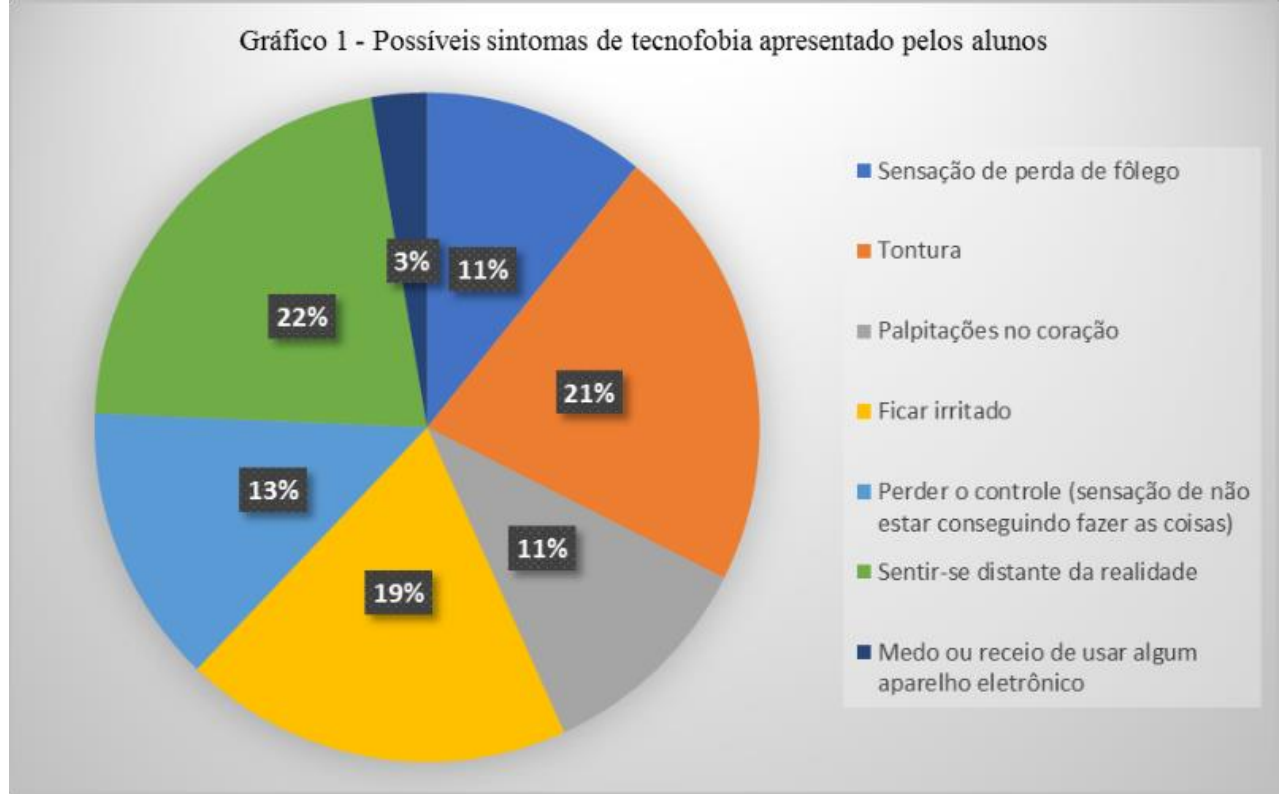

Fonte: elaborado pelos autores, 2021.

Em pesquisa conduzida por Silva e Ferreira (2020), houve a percepção dos efeitos colaterais do isolamento social, ao demonstrar que as pessoas que estavam em isolamento (ou não), estavam sendo afetadas nas suas emoções e relações afetivas. Os alunos podem ter sidos afetados negativamente ao perder sua rotina de ir ao ambiente escolar, não ter o convívio social com seus pares e não terem estrutura domiciliar adequada para realização dos estudos.

Perguntados sobre o aprendizado por meio de aulas on-line (Tabela 1), a maioria afirmou que aprende mais ou menos o conteúdo (83\%), o que demonstra que há uma dificuldade média para o aprendizado nessa modalidade de ensino.

Tabela 1 - aprendizado em meio a aulas remotas.

Você acha que conseguiu/ está conseguindo aprender bem os assuntos pelas aulas remotas?

\begin{tabular}{cc}
\hline Sim & $11 \%$ \\
Não & $6 \%$ \\
Mais ou menos & $83 \%$ \\
\hline Você acha que a tecnologia é importante para a educação? \\
\hline Sim & $89 \%$ \\
Não & $11 \%$ \\
\hline
\end{tabular}

Fonte: elaborado pelos autores, 2021. 
Nesse contexto são contrastantes os resultados apresentados, sendo que $89 \%$ disseram sim para a importância da tecnologia na educação, por outro lado, o aprendizado advindo dessa tecnologia, onde o maior porcentual de 83\% indica "mais ou menos" e apenas 11\% confirmam um aprendizado satisfatório. Esses resultados equiparam com Faustino \& Silva (2020) enfatizando que a falta do ensino presencial dificulta os parâmetros para identificar e avaliar as dificuldades dos alunos.

As estratégias adotadas para lidar com estes problemas são a organização da rotina, melhor ambientação do local de trabalho e estudo, a conversa a fim de melhor informar os filhos e o acompanhamento deles em suas atividades. Durante esse período, a família seria a parceria importante em auxiliar os estudantes em suas tarefas, porém, nem todos os alunos e alunas tem essa base familiar escolarizada para ajudar com as atividades em casa. Lunardi et al. (2021) destacam os problemas enfrentados durante as aulas remotas por pais de alunos e se referem à administração do tempo, à concentração no trabalho e estudos, à internet ruim e a conciliar o estudo do filho com o trabalho.

Perguntados sobre o que aprenderam sobre a tecnologia e seus benefícios e malefícios, os alunos puderam expressar suas opiniões (Quadro 3) de acordo com que o foi aprendido nas aulas sobre a tecnologia na nossa sociedade.

Quadro 3 - Opiniões dos estudantes sobre a tecnologia, seus benefícios e malefícios.

\begin{tabular}{|c|c|}
\hline do & da sua \\
\hline Est & A tecnologia é importante para várias situações em nosso meio, pra melhor nos desenvolvermos. \\
\hline Estudante 2 & $\begin{array}{l}\text { A curiosidade bumana, descompromissada de resultados concretos e livre de qualquer tipo de tutela ou orientação. A } \\
\text { produça científica movida simplesmente por essa curiosidade tem sido capaz de abrir novas fronteiras do conhecimento, } \\
\text { de nos tornar mais sábios e de, no longo prąo, gerar valor e mais qualidade de vida para o ser humano. }\end{array}$ \\
\hline Estudante 3 & $\begin{array}{l}\text { Tecnologia ajuda muito na hora do aprendizado, por vários motivos, mas um aparente é a concentração, é mais fácil } \\
\text { prestar atenção na atividade passada, ainda é mais aparente em ciências e física por ter muitos assuntos, a tecnologia } \\
\text { ajuda mais nessas áreas. A desvantagem é problema de visão, de se comunicar com as outras pessoas, entre vários } \\
\text { outros. }\end{array}$ \\
\hline Estudante 4 & $\begin{array}{l}\text { É importante para a educação fundamental nesse momento de pandemia e também é ruim porque ficamos muito tempo } \\
\text { na frente das telas, ainda mais agora nesse momento tão difícil. }\end{array}$ \\
\hline Estud & $\begin{array}{l}\text { O beneficio é que estão ajudando a nós alunos nas atividades on-line, um maleficio é que muitos pais são contra a } \\
\text { tecnologia. Esse é meu ponto de vista. }\end{array}$ \\
\hline Estu & $\begin{array}{l}\text { Malefícios: Há o risco de engordar, de ter a visão alterada, de sedentarismo e de depressão. As alterações do sono } \\
\text { também são muito comuns; Benefícios: facilidades e muito mais conforto para as tarefas cotidianas. Com esses } \\
\text { mecanismos, podemos fazer diagnósticos precisos, melhorar a qualidade de vida, a comunicaşão e, até mesmo, salvar } \\
\text { vidas. }\end{array}$ \\
\hline Estudante 7 & $\begin{array}{l}\text { A tecnologia é muito importante, ajuda muito e tem muitos beneficios onde pode ser realizado, ajudando a resolver os } \\
\text { problemas. }\end{array}$ \\
\hline Estudante 8 & Podemos fazer diagnósticos precisos, melhorar a qualidade de vida e a comunicaşão. \\
\hline Estudante 9 & $\begin{array}{l}\text { Hoje em dia a tecnologia é muito utilizada, tanto por crianças como por adultos. A tecnologia está se tornando uma } \\
\text { coisa que ninguém vive sem. Porém, algumas pessoas tem dificuldades de ter acesso a essas coisas, pois muitas das vežes, } \\
\text { os pais ou responsáveis não tem condição de dar um aparelho eletrônico moderno aos filhos, a cada atualização de apps } \\
\text { os aparelhos novos vão se tornando melhores e mais caros a tecnologia não deveria ser tão importante, mas infelizmente } \\
\text { ela é. }\end{array}$ \\
\hline Estudante 10 & $\begin{array}{l}\text { Os beneficios são que simplifica muitas coisas e traz a facilidade a tudo e os maleficios é que isso pode nos deixar muito } \\
\text { distante das pessoas. }\end{array}$ \\
\hline Estudante 11 & $G$ \\
\hline
\end{tabular}


Os benéficos são as pessoas ficarem mais conectadas, facilidades de pesquisa ou descobrir algo o ruim, os malefícios são

Estudante 12 que a pessoa pode ser tornar viciada ou ter problema na visão e na coluna.

Fonte: elaborado pelos autores, 2021.

Sobre essa questão, os estudantes apontam para a necessária utilização da tecnologia durante a pandemia, o conforto de realizar as atividades em casa, a conexão entre as pessoas por meio das redes sociais, a grande quantidade de informação e resolução de problemas na área da saúde demonstrando que a explicação prévia do tema tecnologia na sociedade a partir da SD foi compreendida, pois levou duas visões sobre a utilização desse conhecimento na sociedade e suas consequências, sejam elas positivas ou negativas.

Dentre os malefícios, os alunos listaram problemas na visão, ruídos na comunicação, informações falsas ou mentiras (fake news), pais que são contra o uso de tecnologias como o smartphone, sedentarismo, depressão, distanciamento das pessoas e doenças ligadas a ergonomia. É válido ressaltar o conceito de saúde como um bem-estar físico e mental, onde ambos se complementam e conforme explicitado no (Quadro 4) os estudantes inferem sobre os benefícios e malefícios da pandemia, que de certa forma aumentam ou estreitam os laços familiares, a depender do contexto familiar e até acarretar problema de saúde.

Corroboramos com Maia \& Dias (2020) ao enfatizar a saúde entrelaçada ao bem-estar físico e psicossocial e os problemas agravados pela pandemia no prolongamento do confinamento, falta de contato com colegas, medo de contágio e a carência de espaços reservados aos estudos definidos na moradia tornam os estudantes menos ativos e produtivos. Os autores trazem ainda, que a alimentação escolar servida como merenda contribui com o desenvolvimento do aluno, já que não ocorre essa distribuição no ensino remoto, o que gera estresse e provoca frustrações na saúde mental. O estudo realizado por Cao et al. (2020) aponta essa interligação entre os efeitos da pandemia em estudantes na China, onde 24,9\% dos entrevistados apresentaram algum grau de ansiedade, ou seja, o fator saúde e bem-estar físico afetado pelos efeitos do vírus que levou ao isolamento social na vida dos estudantes e afetou no desenvolvimento dos estudos.

Por fim, foi pedido aos alunos que expressassem as dificuldades, vantagens ou outra informação que considerassem importante sobre as aulas remotas (Quadro 4). Nesse quesito os alunos elencaram a necessidade de uma nova rotina de estudos, a falta de um professor presente para ajudar a tirar as dúvidas e ajudar nas realizações das atividades, dificuldades de aprendizagem de forma remota e anseios para a volta as aulas de forma presencial. 
Quadro 4 - Dificuldades, vantagens e outras informações que os alunos expressaram sobre as aulas on-line.

\begin{tabular}{|c|c|}
\hline Estuc & $\begin{array}{l}\text { Adote uma rotina similar à que teria se fosse para a instituição de ensino: acordar cedo, vestir-se adequadamente, } \\
\text { tomar o café da manhã no horário normal e focar nas atividades seguindo o cronograma da sua turma. }\end{array}$ \\
\hline Estudante 2 & $\begin{array}{l}\text { As minhas dificuldades são que eu fico perdida e muitas das vezes fico sem fazer (as atividades), vantagens que não } \\
\text { estamos na escola tendo o risco de pegar a Covid-19. }\end{array}$ \\
\hline Estudante 3 & Vantagens não vejo muitas, pois, acho que não aprendemos $100 \%$ nas aulas remotas. \\
\hline Estudante 4 & Dificuldades tenho bastante em atividades, às vezes, em explicações também. \\
\hline Estudante 5 & Tem pessoas que têm dificuldade, e isso dificulta um pouco, então em ambas as partes são importantes. \\
\hline Estudante 6 & Dificuldade em algumas matérias e está tudo muito difícil, mas ok ... \\
\hline Estudante 7 & Os estudos remotos trazem muito mais dívidas. \\
\hline Estudante 8 & $\begin{array}{l}\text { Muito conteúdo pela internet, além disso, mais tempo para estudo, mas acaba sendo que alguns estão desvalorizando e } \\
\text { bloqueando mentalmente que esse tipo de ferramenta é melhor ou superior, algo que só é você e a tela onde passa as } \\
\text { informações, informaçôes que tem categorias, subcategorias, e tem milhares de textos que gênios não tiveram contato, } \\
\text { algo como "você é pobre demais para aprender isso", "você é alto, gordo ou feio para faz̨er isso", "isso é difícil demais de } \\
\text { fazer", "não tem muito conteúdo sobre isso", isso corrói a mente de pessoas fracas, elas usam isso de desculpas e se } \\
\text { tornam ignorantes por isso, a Internet tem tanto conteúdo que se procurarmos pouco, [...] a internet tem milhares de } \\
\text { conteúdos que são ótimos para o crescimento mental, mas há doentes nela, como qualquer coisa por aí afora, conteúdos } \\
\text { de séculos e anos de estudo por várias pessoas com capacidades enormes de conhecimento, acabam sendo rasurados por } \\
\text { pessoas ignorantes que leram } 2 \text { palavras comparadas com as milhares de pessoas acadêmicas leram e estudaram sobre } \\
\text { algo, a Internet de fato é uma das maiores criaçôes da história, mas por causa de pessoas fracas e ignorantes ela se torna } \\
\text { algo como uma arma. }\end{array}$ \\
\hline studante 9 & $O$ \\
\hline
\end{tabular}

Fonte: elaborado pelos autores, 2021.

As questões sobre os benefícios e malefícios das tecnologias e as dificuldades e vantagens das aulas on-line, para Pasini, Carvalho \& Almeida (2020), enaltecem e preconizam aulas presenciais e entrelaçam ainda, a questões dos problemas de saúde apresentados nos Quadros 3 e 4 gerados pelo distanciamento social e o isolamento social que estreita relações e enfraquece laços, onde é necessário buscar o auxílio dos profissionais de saúde em parceria com a educação, a tele saúde. Visando melhorias e relacionando sobre o lado bom e ruim das tecnologias na melhoria da educação e saúde, os autores supracitados defendem ainda, que o ensino remoto não substitui as afetividades do presencial.

Nesse sentido, a educação remota apresenta suas fragilidades e podem ser um fator que desencadeia problemas de saúde mental como a tecnofobia, por outro lado, há necessidade de utilização dessas tecnologias em sala de aula a partir do letramento digital, pois, vivemos num mundo onde as ferramentas evoluem rapidamente e as formações a distância se tornam uma necessidade.

\section{CONSIDERAÇÕES FINAIS}

Por meio da sequência didática aplicada em aulas remotas foi possível levar aos alunos conhecimentos básicos sobre a tecnologia no nosso cotidiano e apresentar o transtorno da tecnofobia. No sentido da SD atender a sua função, foi possível levar aos educandos a capacidade de identificar e buscar soluções, os estudantes tiveram acesso ao conhecimento sobre um novo transtorno psicossocial e pela utilização da cartilha tiveram a instrução de buscar ajuda profissional de um psicólogo ou terapeuta caso sintam que seus sintomas tenham avançado, além de esclarecer os problemas da situação de estudo, ampliar o conhecimento científico 
acerca da tecnologia e da tecnofobia e com isso ampliar o nível de consciência quanto a problemática da tecnofobia no nosso cotidiano.

Pelo questionário aplicado foi possível perceber que as aulas remotas podem ter afetado a vida estudantil dos entrevistados, já que apontaram sintomas relacionados a mudança de ambiente escolar para estudos dentro de casa e uso constante de tecnologia, o que gerou sentimentos de sentir-se distante da realidade, tontura e ficarem irritados e abrem discussões do quanto a tecnologia pode substituir o ensino presencial e as interrelações dentro do universo escolar.

Por fim, a pesquisa não tem função de gerar diagnósticos, mas fazer um levantamento inicial sobre como a tecnologia pode gerar soluções ou problemas na sociedade. Dessa forma, pesquisas mais amplas devem ser feitas em busca de conhecer, aprofundar e buscar alternativas para evitar, tratar e diminuir a tecnofobia entre os jovens estudantes.

\section{Agradecimentos}

A Coordenação de Aperfeiçoamento de Pessoal de Nível Superior - CAPES, a Universidade Aberta do Brasil (UAB) e ao Instituto Federal da Bahia - IFBA campus Vitória da Conquista.

\section{Conflitos de interesses}

Os autores declaram que não há conflitos de interesse. Todos os autores estão cientes da submissão do artigo.

\section{Contribuição dos autores}

Todos os autores contribuíram de maneira substancial para a realização deste trabalho.

\section{REFERÊNCIAS}

Cao, W., Fang, Z., Hou, G., Han, M., Xu, X., Dong. J., \& Zheng, J. (2020) The psychological impact of the COVID-19 epidemic on college students in China. Elsevier, Psychiatry Reseach, 287, 1-5. DOI: $\underline{10.1016 / \text { i.psychres.2020.112934 }}$

Centro Regional de Estudos para o Desenvolvimento da Sociedade da Informação - Cetic. (2013). Tecnologias e educação o uso da Internet por alunos brasileiros de Ensino Fundamental e Médio, 5(2). Obtido em: https://www.cetic.br/media/docs/publicacoes/6/panorama-setorial-agosto-2013.pdf

Centro Regional de Estudos para o Desenvolvimento da Sociedade da Informação - Cetic. (2020). Pesquisa TIC domicílios 2020.20 Obtido em: https://www.cetic.br/media/docs/publicacoes/2/20211124201505/resumo executivo tic domicilios 2020.pd $\underline{f}$

Conselho Regional de Corretores de Imóveis da Bahia - CRECI-BA. (2018). Mercado Imobiliário Aquecido na Suiça Baiana. Obtido em: http://www.creciba.gov.br/mercado-imobiliario-aquecido-na-suica-baiana/ 
Cunha, C. E. X., Moreira, M. M. G., Castro, L. R., Oliveira, L. B. B., Carvalho, A. S., Souza, A. M. A., \& Ribeiro, M. V. M. R. (2021). Isolamento social e ansiedade durante a pandemia da COVID-19: uma análise psicossocial. Brazilian Journal of Health Review, 4(2), 9022-9032. https://doi.org/10.34119/bjhrv4n2-409.

Faustino, L. S. S., \& Silva, T. F. R. S. (2020). Educadores frente à pandemia: dilemas e intervenções alternativas para coordenadores e docentes. Revista Boletim de Conjuntura, 3 (7), 53-64. http://doi.org/10.5281/zenodo.3907086

Flick, U. (2009). Introdução à pesquisa qualitativa. Tradução Joice Elias Costa. (3. Ed.). Porto Alegre: Artmed.

Freire, P. (1987). Pedagogia do Oprimido. Rio de Janeiro: Paz e Terra.

Instituto Brasileiro de Geografia e Estatística (IBGE). (2021). Cidades e Estados: Vitória da Conquista. Obtido em: https://www.ibge.gov.br/cidades-e-estados/ba/vitoria-da-conquista.html

Lunardi, N. M. S. S., Nascimento, A., Sousa, J. B., Silva, N. R. M., Pereira, T. G. N., \& Fernandes, J. S. G. (2021). Aulas Remotas Durante a Pandemia: dificuldades e estratégias utilizadas por pais. Educação \& Realidade, 46(2), 1-22. http://dx.doi.org/10.1590/2175-6236106662

Maia, B. R., \& Dias, P. C. (2020). Ansiedade, depressão e estresse em estudantes universitários: o impacto da Covid-19. Estudos de Psicologia (Campinas), Campinas, 1(37), 1-8. https://doi.org/10.1590/1982$\underline{0275202037 \mathrm{e} 200067}$

Maranhão. (2015). Secretaria de Educação do Estado do Maranhão. Eixo Tecnologia. Obtido em: https://www.educacao.ma.gov.br/eixo-tecnologia/

Mehta, P.; McAuley, D. F.; Brown, M.; Sanchez, E.; Tattersall, R. S.; \& Manson, J. J. (2020). COVID-19: consider cytokine storm syndromes and immunosuppression. The Lancet, (395), 1034-1035. https://doi.org/10.1016/S0140-6736(20)30628-0

Moura, M. A., Silva, M. O., \& Leal, T. L. M. C. (2021). Elaboração e validação de sequências didáticas sobre ecologia e conservação da fauna para o ensino de Biologia. Braz̧ilian Journal of Development, Curitiba, 7(12), 113664-113681. DOI: https://doi.org/10.34117/bjdv7n12-243

Pasini, C. G. D., Carvalho, E., \& Almeida, L. H. C. (2020). A educação híbrida em tempos de pandemia: algumas considerações. FAPERGS.

Porto, L. R., Santana-Júnior, G., Nascimento, H. M. (2017). Rede urbana do estado da Bahia: o caso de Vitória da Conquista (BA). Revista de Desenvolvimento Econômico - RDE, 2(37), 82-110. https://revistas.unifacs.br/index.php/rde/article/view/4841/3231

Ramos, C.V., Camelo, C. V., Ferreira, E. S., Pereira, F. A., Almeida, J. M., Silva, L. P., Matos, M. L. S., Câncio, A. M. S., \& Cordeira, T. N. (2020). Tecnofobia em tempos de educação remota. UniFTC: Vitória da Conquista. Obtido em:

https://www.academia.edu/44583943/TECNOFOBIA EM TEMPO DE EDUCA\%C3\%87\%C3\%83O RE $\underline{\text { MOTA }}$

Schneider, E. M., Fujii, R. A. X., \& Corazza, M. J. (2017). Pesquisas Quali-Quantitativas: contribuições para a pesquisa em ensino de ciências, Revista Pesquisa Qualitativa. São Paulo (SP), (5)9, 569-584. https://editora.sepq.org.br/rpq/article/view/157/100

Schoch, A. (2016). Tecnofobia: Professor, você sofre desse mal? Associação Beneficente dos Professores Públicos Ativos e Inativos do Estado Rio de Janeiro - APPAI. Obtido em: https://www.appai.org.br/tecnofobia-professorvoce-sofre-desse-mal// 
Silva, M. O.; \& Ferreira, E. S. (2020). Percepção sobre o isolamento social devido ao coronavírus (Covid-19) em Vitória da Conquista - BA. In: Tavares, T. R. P., \& Medeiros, L. H. C. (Org.) Ciências da saúde no Brasil: contribuições para enfrentar os desafios atuais e futuros (p. 23-39). Campina Grande: Editora Amplla.

Silva, M. O. (2019). Lourinha e sua turma: os quadrinhos como metodologia de ensino em temáticas socioambientais. Educação Ambiental em Ação, 17(67), 1-15. https://www.revistaea.org/artigo.php?idartigo=3585

Silva, M. O. (2021). Lourinha e sua turma. Maringá: Editora Viseu.

Silva, M. O.; \& Moura, M. A. (2021). Toca o som DJ! Sequência didática sobre sexualidade com o uso de músicas e videoclipes. Journal of Education, Science and Health, (1) 3, 1-17. https://doi.org/10.52832/jesh.v1i3.30

Sociedade Brasileira de Infectologia. (2020). Associação Médica Brasileira (AMB). Informa a sociedade brasileira de Infectologia (SBI) sobre o novo coronavirus. Obtido em: https://cbr.org.br/wpcontent/uploads/2020/03/Informativo-em-PDF-CoV-12-03-2020.pdf.pdf

Thiollent, M. (1986). Metodologia da Pesquisa-Ação. São Paulo: Cortez.

Xing, Z. L., \&a Zhi, B. X. Z. (2020). The epidemiological characteristics of an outbreak of 2019 novel coronavirus diseases (COVID-19) in China. Epidemiology Working Group for NCIP Epidemic Response, Chinese Center for Disease Control and Prevention, 41(2), 145-151. DOI: 10.3760/cma.j.issn.0254-6450.2020.02.003. 